\title{
The Uncertainties of Population Research: Challenges and Opportunities
}

An estimated 7.7 billion people are living in the world today, and that total is expected to reach around 8.5 billion in 2030, 9.7 billion in 2050, and further increase to 11.2 billion by 2100 (1). In 1987, the world's population hit 5 billion. To mark the date, the Governing Council of the United Nations Development Programme (UNDP) established the annual World Population Day to be observed on July 11 every year since 1989.

The 32nd World Population Day (WPD) is coming. In this second year of the coronavirus disease 2019 (COVID-19) pandemic, the United Nations Population Fund (UNFPA) has expressed continued concern over various population issues such as changing fertility rates, healthcare systems, sexual and reproductive health, and gender equality against the backdrop of the ongoing pandemic.

For the current population development, it is not difficult to find some trend changes, such as the recognized global demographic "megatrends," i.e., population growth, population aging, international migration, and urbanization. The population size in the present and future as mentioned above, indicates that the world population will continue to grow during a certain period in the future. However, the global fertility is projected to fall from 2.5 children per woman in 2019 to 2.2 in 2050, and life expectancy at birth is expected to rise from 72.6 years in 2019 to 77.1 years in 2050 (1). The decreasing fertility combined with increasing longevity makes population aging inevitable. In addition, although international migration usually contributes much less to population change compared with births or deaths, its effect is undeniable, given that the world is accelerating migration and urbanization.

The results of the Seventh National Population Census of China that was recently released also shows China's similar status. First, the fertility of China is exceptionally low. The total fertility rate in 2020 was only 1.3 children per woman, which is far below the replacement level (2). In addition, China is experiencing rapid population aging and persons aged 60 years or over account for $18.70 \%$ of the total population, which was an increase of $5.44 \%$ compared with the Sixth National Population Census results conducted in 2010 (3). In addition, more and more populations are involved in migration. In 2020, there were 375.8 million individuals in the floating population in China, with an increase of $69.73 \%$ compared with that in 2010. Furthermore, nearly 902 million individuals lived in urban areas, accounting for $63.89 \%$ of the total population (4).

However, the outbreak and global pandemic of COVID-19 reminds us that we should not ignore the uncertainty of population development, especially short term trends compared to what seems to be regularity in the long run. The uncertainties are partly due to the huge population of the world, especially in China, and also come from the internal characteristics such as the polymorphism of population structure changes and the uncertain development of external environments to include increasing adverse climate and ecosystem changes, regional conflicts and wars, and unpredictable public health emergencies such as the pandemic.

In this special issue, we invited colleagues from the UNFPA, United Nations Population Division, Princeton University, Duke University, University of British Columbia, Peking University, and Renmin University of China to report their latest findings on challenges and opportunities under the population trends around the world. Gu et al. assessed major trends in population growth around the world and variations across regions and countries (5). Luo et al. estimated the trends and challenges for population and health during population aging in China ( 6 ). Wang et al. analyzed the factors of Chinese population fertility changes from the perspective of economics and education ( 7 ). Finally, Qian et al. examined the China-US difference in attitudes toward COVID-19 and evaluated the role of belief in science to explain the differences (8).

The findings from this special issue further confirmed the trend of growth in the world's population at a slower pace, the substantial variations in population trends across regions and countries, and important role of population momentum in determining future population growth. For China, the increases in life expectancy, declines in fertility rate and consequent population aging, and increasing life expectancy with disability are predicted. However, this special issue also indicated uncertainties in future population growth and multiple states of future trends of 
population structure change - that is the complex effects of economic development and education on fertility rate, the uncertainties and inaccuracies in urbanization rate statistics, and various public trust in science and public support for population health measures will all impact the fertility, migration, and mortality of a population.

In the context of approaching the 2030 Sustainable Development Goals, the uncertainties in population research and the reasons behind them put forward challenges to social governance and provide important opportunities for us to make changes. To deal with these internal and external challenges of population research, it is urgent to review and further explore the complementarities between economic development and population development and to improve global policy, institutional support structures, and dynamic evaluation. Timely adjustment, innovations, and perfection of population health strategies are needed, especially for females, older adults, floating populations, and populations with disability.

doi: $10.46234 / \mathrm{ccdcw} 2021.156$

${ }^{1}$ Institute of Population Research, Peking University, Beijing, China; ${ }^{2}$ APEC Health Science Academy, Peking University, Beijing, China.

Submitted: June 24, 2021; Accepted: July 06, 2021

\section{REFERENCES}

1. United Nations. Population. 2021. https://www.un.org/en/global-issues/population. [2021-6-18].

2. China.org.cn. SCIO briefing on 7th national population census. 2021. http://www.china.org.cn/china/2021-05/13/content_77495036_11.htm. [2021-618].

3. National Bureau of Statistics of China. Communiqué of the seventh national population census (No. 5) - age composition. 2021. http://www.stats.gov.cn/ english/PressRelease/202105/t20210510_1817190.html. [2021-6-18].

4. National Bureau of Statistics of China. Communiqué of the seventh national population census (No. 7) - urban and rural population and floating population. 2021. http://www.stats.gov.cn/english/PressRelease/202105/t20210510_1817192.html. [2021-6-18].

5. Gu DN, Andreev K, Dupre ME. Major trends in population growth around the world. China CDC Wkly 2021;3(28):604-13. http://dx.doi.org/10.46234/ccdcw2021.160.

6. Luo YN, Su BB, Zheng XY. Trends and challenges for population and health during population aging-China, 2015-2050. China CDC Wkly 2021;3(28):593 - 8. http://dx.doi.org/10.46234/ccdcw2021.158.

7. Wang YR, Fan HY, Guo C. Trend and factors of population fertility changes from the perspective of economics and education-China, 1949-2020. China CDC Wkly 2021;3(28):599 - 603. http://dx.doi.org/10.46234/ccdcw2021.159.

8. Qian Y, Jin YA, Xie Y. Belief in science and attitudes toward COVID-19: a demographic standardization approach to China-US comparison, 2020. China CDC Wkly, 2021. http://dx.doi.org/10.46234/ccdcw2021.157

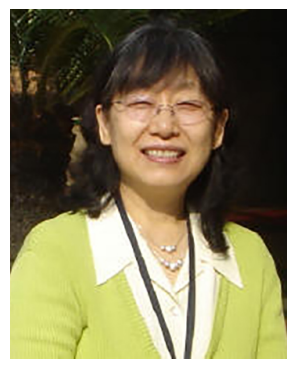

Xiaoying Zheng, MD, PhD

Dean, APEC Health Science Academy, Peking University

Boya Distinguished Professor, Institute of Population Research, Peking University

Fellow of The World Academy of Sciences (TWAS) 